\title{
Você sabia que a falta de vitamina B12 pode desencadear doenças neurológicas?
}

\author{
Did you know that a lack of vitamin B12 can trigger neurological diseases? \\ ¿Sabías que la falta de vitamina B12 puede desencadenar enfermedades neurológicas?
}

Recebido: 08/02/2022 | Revisado: 14/02/2022 |Aceito: 20/02/2022 | Publicado: 02/03/2022

\author{
Ana da Silva Torres Viana \\ ORCID: https://orcid.org/0000-0002-1636-5587 \\ Instituto Federal Goiano, Brasil \\ E-mail: ana.viana@estudante.ifgoiano.edu.br \\ Lorrane Soares dos Santos \\ ORCID: https://orcid.org/0000-0002-0519-2246 \\ Instituto Federal Goiano, Brasil \\ E-mail: lorrane.soare.santos@gmail.com \\ Maria Fernanda Pasqualotto \\ ORCID: https://orcid.org/0000-0002-1809-8160 \\ Instituto Federal Goiano, Brasil \\ E-mail: mariafer_p@hotmail.com \\ Talita Ribeiro Lemos Ferreira \\ ORCID: https://orcid.org/0000-0001-7869-4282 \\ Instituto Federal Goiano, Brasil \\ E-mail: talitarlemos@hotmail.com \\ Geovana Rocha Placido \\ ORCID: https://orcid.org/0000-0002-3028-7191 \\ Instituto Federal Goiano, Brasil \\ E-mail: geovana.placido@ifgoiano.edu.br
}

\begin{abstract}
Resumo
A vitamina B12, cianocobalamina ou cobalamina é uma vitamina do complexo B, hidrossolúvel e de origem bacteriana, sintetizada exclusivamente por microrganismos, e por esta razão, ela é encontrada apenas em alimentos de origem animal. Para que haja a absorção da cobalamina no sistema digestivo, é essencial que o trato gastrointestinal esteja em prefeitas condições, sendo que esse micronutriente pode ser encontrado em dietas a base de proteínas. A má absorção da cobalamina proveniente de alimentos é a principal causa de deficiência dessa vitamina em adultos. A apresentação clínica da deficiência de B12 é insidiosa e inclui manifestações hematológicas, manifestações gastrointestinais e manifestações neurológicas. Para a análise da problemática foi utilizada uma pesquisa sistemática e ordenada a partir de dados eletrônicos. Sendo assim, tendo em vista a importância da vitamina B12 e as consequências pela sua deficiência no organismo, este estudo de revisão bibliográfica de natureza qualitativa objetivou sintetizar o conhecimento sobre as relações de doenças neurológicas com a falta de vitamina B12, abordando tópicos de caráter educativo que visam a conscientização sobre o tema, prevenção de males e dar suporte ao desenvolvimento de tratamentos reparativos. Após diversas abordagens temáticas referentes ao assunto, obteve-se com este trabalho a necessidade de esclarecer à toda sociedade a importância da cobalamina para o desenvolvimento e funcionamento correto do organismo, para que esse assunto não se torne futuramente um grave problema de saúde pública.
\end{abstract}

Palavras-chave: Cobalamina; Anemia; Alzheimer; Parkinson.

\begin{abstract}
Vitamin B12, cyanocobalamin or cobalamin is a B-complex vitamin, water-soluble and of bacterial origin, synthesized exclusively by microorganisms, and for this reason, it is found only in foods of animal origin. For the absorption of cobalamin in the digestive system, it is essential that the gastrointestinal tract is in perfect condition, and this micronutrient can be found in protein-based diets. Malabsorption of cobalamin from food is the main cause of vitamin deficiency in adults. The clinical presentation of B12 deficiency is insidious and includes hematologic manifestations, gastrointestinal manifestations, and neurologic manifestations. For the analysis of the problem, a systematic and ordered research was used based on electronic data. Therefore, in view of the importance of vitamin B12 and the consequences of its deficiency in the body, this qualitative literature review study aimed to synthesize knowledge about the relationship between neurological diseases and the lack of vitamin B12, addressing topics of an educational nature. aimed at raising awareness on the subject, preventing diseases and supporting the development of reparative treatments. After several thematic approaches related to the subject, this work obtained the need to clarify to the whole society the importance of cobalamin for the development and correct functioning of the organism, so that this subject does not become a serious public health problem in the future.
\end{abstract}

Keywords: Cobalamin; Anemia; Alzheimer's; Parkinson's. 


\begin{abstract}
Resumen
La vitamina B12, cianocobalamina o cobalamina es una vitamina del complejo B, hidrosoluble y de origen bacteriano, sintetizada exclusivamente por microorganismos, por lo que se encuentra únicamente en alimentos de origen animal. Para la absorción de la cobalamina en el sistema digestivo es fundamental que el tracto gastrointestinal esté en perfectas condiciones, y este micronutriente se puede encontrar en dietas basadas en proteínas. La malabsorción de cobalamina de los alimentos es la principal causa de deficiencia de vitaminas en adultos. La presentación clínica de la deficiencia de B12 es insidiosa e incluye manifestaciones hematológicas, gastrointestinales y neurológicas. Para el análisis del problema se utilizó una investigación sistemática y ordenada en base a datos electrónicos. Por lo tanto, en vista de la importancia de la vitamina B12 y las consecuencias de su deficiencia en el organismo, este estudio cualitativo de revisión de la literatura tuvo como objetivo sintetizar el conocimiento sobre la relación entre las enfermedades neurológicas y la falta de vitamina B12, abordando temas de carácter educativo. en la sensibilización sobre el tema, la prevención de enfermedades y el apoyo al desarrollo de tratamientos reparadores. Luego de varios abordajes temáticos relacionados con el tema, este trabajo obtuvo la necesidad de aclarar a toda la sociedad la importancia de la cobalamina para el desarrollo y correcto funcionamiento del organismo, a fin de que este tema no se convierta en un futuro en un grave problema de salud pública.
\end{abstract}

Palabras clave: Cobalamina; Anemia; Alzhéimer; Parkinson.

\title{
1. Introdução
}

A vitamina B12, cianocobalamina ou cobalamina é uma vitamina do complexo B, hidrossolúvel e de origem bacteriana, sintetizada exclusivamente por microrganismos, e por esta razão, ela é encontrada apenas em alimentos de origem animal (Rémond, 2019). Carnes e leites de animais ruminantes herbívoros são boas fontes de B12 para humanos. Os ruminantes adquirem o nutriente essencial B12 por meio de uma relação simbiótica com bactérias dentro do corpo (Watanabe et al., 2017; Maia et al., 2019). Segundo Rowley (2019), embora a vitamina B12 seja produzida por bactérias intestinais, comumente encontradas no corpo humano, essas bactérias se localizam na parte final do trato digestivo, desta forma, a síntese ocorre fora do local de absorção dos nutrientes no corpo. A vitamina B12 sintetizado no estômago é absorvido no intestino, transferido para o sangue e armazenado no fígado e músculos do animal ou segregados no leite (Paniz et al., 2005). Em decorrência disto, a vitamina B12 deve ser necessariamente consumida através da alimentação.

A necessidade diária mínima de vitamina B12 para seres humanos após os 14 anos de idade (fora do período de gestação ou lactação) é de 2,4 $\mu \mathrm{g}$ /dia, sendo a necessidade de absorção de $1 \mu \mathrm{g}$ /dia, quantidade completamente coberta por um alimento misto normal contendo entre 5 e $30 \mu \mathrm{g}$ de cobalamina absorvida de 1 a $5 \mu \mathrm{g}$. 10 (Brasil, 2012). Alguns alimentos fermentados possuem vitamina B12, que são extraídos através das bactérias que causam fermentação. Entretanto, na maioria dos casos, a quantidade existente não é suficiente. Embora o teor de B12 do leite bovino não seja relativamente alto ao comparar as carnes bovinas, o leite e seus derivados (iogurte, queijo) são grandes fontes da vitamina porque a ingestão do leite ou dos produtos lácteos é alta em várias populações. A concentração de B12 no leite bovino depende de muitos fatores, entre tipo de vacas, estado reprodutivo e hora da ordenha (Duplessis, 2016).

De acordo com Herrmann et al., (2003) pelo fato desse micronutriente não estar disponível em alimentos de origem vegetal, uma vez que plantas não produzem e não precisam deste nutriente, a população vegetariana se torna mais propensa a apresentarem deficiência da vitamina. No entanto, pode se encontrar fonte de vitamina B12 em vegetais, desde que estes estejam contaminados com solo, estudos apontam que o uso de alimentos enriquecidos com vitamina B12, plantas comestíveis, cogumelos e leguminosas podem melhorar os níveis séricos de vitamina B12, entretanto raramente encontra uma quantidade considerável do nutriente e a absorção é inexpressiva (Bravo et al., 2014). Sendo assim, indivíduos que optem por dietas de vegetariano estrito e veganismo devem fazer a suplementação para garantir uma dieta saudável (Ribeiro et al., 2010; CombsJúnior, 2012).

A deficiência de cobalamina pode trazer consequências além da anemia megaloblástica, onde estudos em andamento sugerem relação com diversas doenças neurológicas, tais como alterações de humor, comprometimento cognitivo, depressão, Alzheimer e hipotonia (Madureira et al., 2018; Serin \& Arslan, 2019). Com o intuito de oferecer produtos de qualidade para os 
consumidores, desde 1998 a legislação brasileira prevê a adição de nutrientes como alternativa de suplementação, tendo em vista a existência de locais com elevada deficiência de micronutrientes, ficando estabelecido a Portaria no 31, de 13/01/1998 (Brasil, 1998; Abrantes \& Tabai, 2013). Diversos trabalhos estão sendo desenvolvidos para contemplar a demanda nutricional de toda a população, incluindo os veganos e vegetarianos, propondo alternativas de fontes alimentares da vitamina B12, tais como macarrão de quinoa e sêmola e barra de cereal, os dois produtos fortificados com vitamina B12 (López, 2019; Costa, 2018).

Sendo assim, tendo em vista a importância da vitamina B12 e as consequências pela sua deficiência no organismo, este estudo de revisão bibliográfica de natureza qualitativa pretende sintetizar o conhecimento sobre as relações de doenças neurológicas com a falta de vitamina B12, abordando tópicos de caráter educativo que visam a conscientização sobre o tema, prevenção de males e possibilitar o desenvolvimento de tratamentos reparativos.

\section{Metodologia}

Sendo assim, foi utilizada uma pesquisa sistemática e ordenada a partir de dados eletrônicos (periódicos científicos e documentos técnicos especializados no assunto). Revisões sistemáticas e meta-análises são ferramentas essenciais para resumir evidências de forma precisa e confiável. As revisões sistemáticas devem ser relatadas de forma completa e transparente para permitir que os leitores avaliem os pontos fortes e fracos da investigação (liberati et al.,2009). Para a análise quantitativa das publicações, foram utilizados os artigos indexados nas plataformas Periódicos Capes, Science Direct e Google Acadêmico, utilizando de publicações nacionais e internacionais acessadas em dezembro de 2021 e janeiro de 2022.

A pesquisa foi realizada através da busca de artigos relacionados a deficiência de vitamina B12, alimentos fontes de vitamina B12, doenças neurológicas causadas pela deficiência de vitamina B12, onde grande maioria foram publicados durante o período compreendido entre 2016 e 2022. Na busca aplicada as bases de dados, inicialmente foram selecionados 73 artigos, 03 artigos duplicados foram registrados apenas uma vez. Após a leitura dos resumos 24 publicações foram excluídas por não ter abordagem consistente com a temática em questão. Sendo assim, 46 publicações foram selecionadas para leitura na íntegra, seguindo fluxograma representado na Figura 1. De modo mais detalhado, vide Tabela 1 com os dez principais trabalhos que embasaram diretamente o tema abordado. 
Figura 1. Fluxograma do processo de seleção de dados.

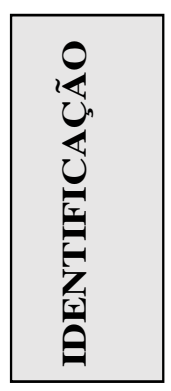

Bases de dados para seleção dos artigos:

Periódicos Capes, Science Direct e Google Acadêmico.
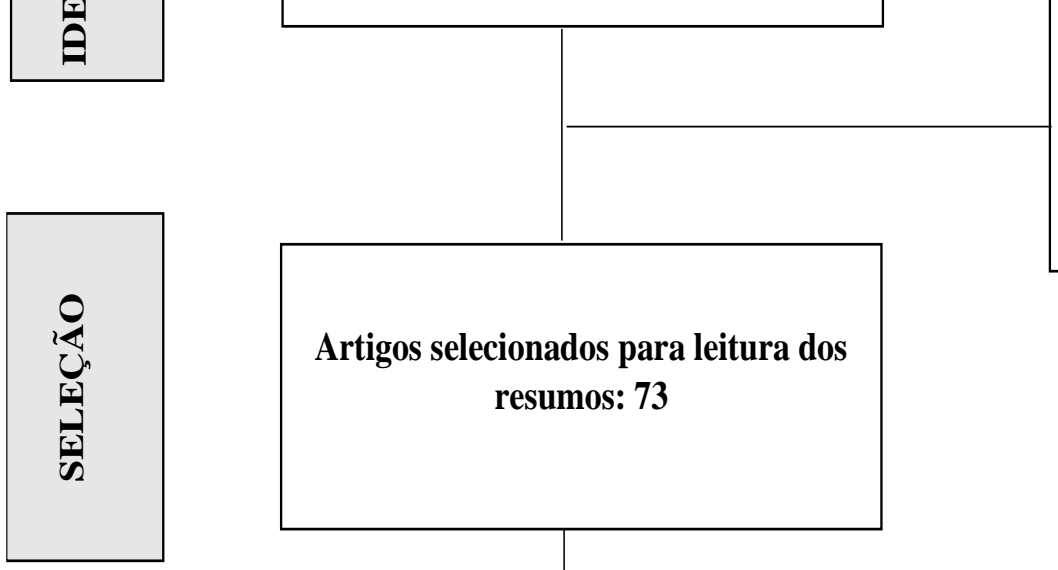

Artigos duplicados: 03

Artigos excluídos por falta de consistência com o tema em questão:

24
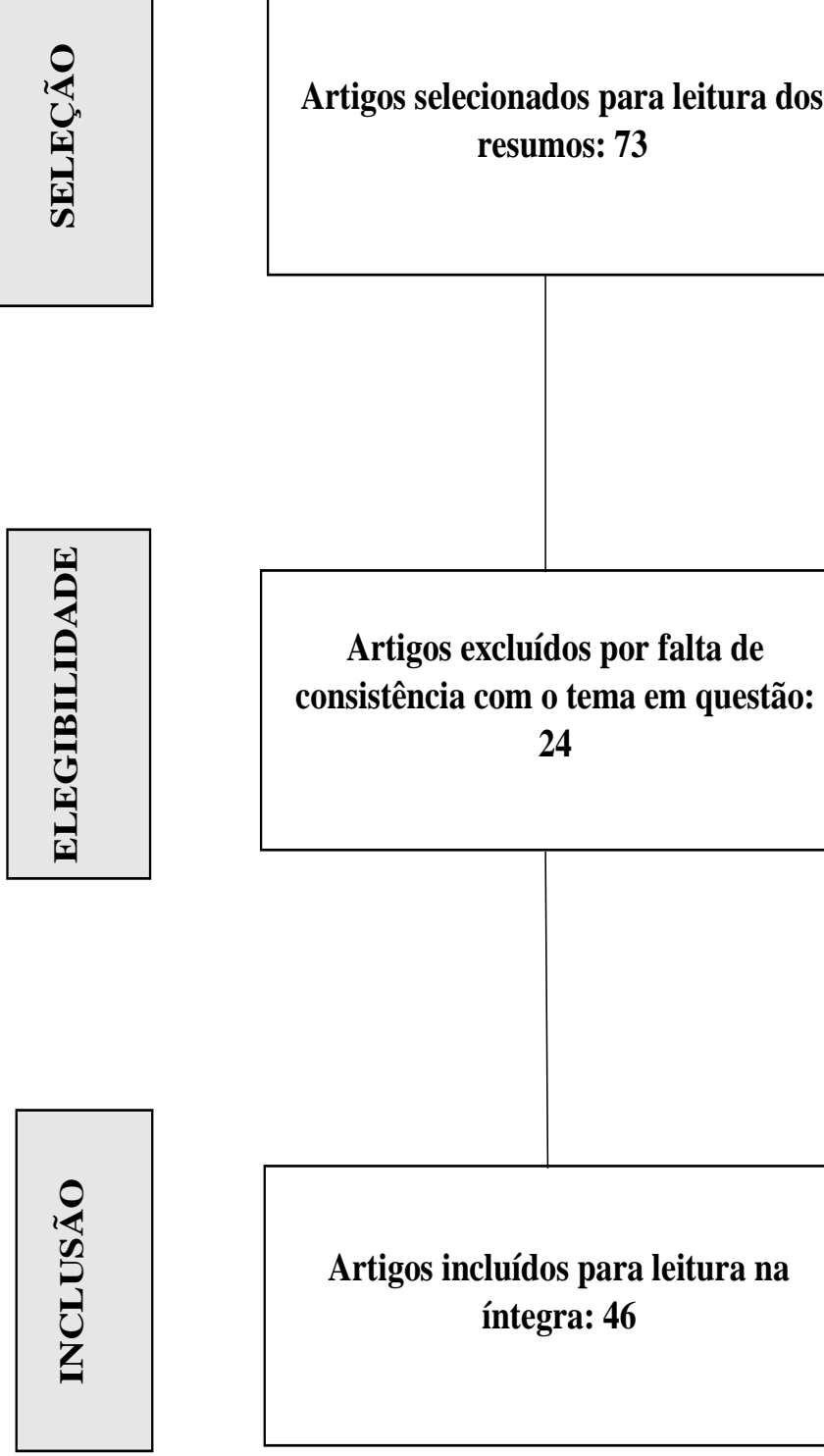
resumos: 73

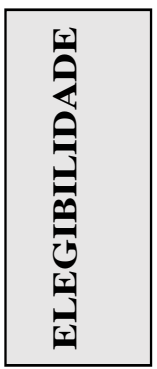

Artigos incluídos para leitura na íntegra: 46

Fonte: Elaborado pelas autoras. 
Tabela 1 - Trabalhos que embasaram diretamente o tema abordado.

\begin{tabular}{|c|c|c|}
\hline Autores & Variáveis utilizadas & Título do artigo e ano da publicação \\
\hline $\begin{array}{l}\text { 1. Alpers, D. H., \& } \\
\text { Russell-Jones, G. }\end{array}$ & $\begin{array}{l}\text { Fator intrínseco (FI), células parietais da } \\
\text { mucosa gástrica humana, absorção da } \\
\text { vitamina essencial cobalamina (Cbl) no íleo. }\end{array}$ & $\begin{array}{l}\text { Gastric intrinsic factor: The gastric and small } \\
\text { intestinal stages of cobalamin absorption, } 2013 \text {. }\end{array}$ \\
\hline 2. Bravo, P., \& Ibarra, J. & $\begin{array}{l}\text { Vitamina B12 em vegetais; alimentos que } \\
\text { podem melhorar os níveis séricos de } \\
\text { vitamina B12 }\end{array}$ & $\begin{array}{l}\text { Compromiso neurológico y hematológico por déficit } \\
\text { de vitamina B12 en lactante hijo de madre } \\
\text { vegetariana: Caso Clínico, } 2014 \text {. }\end{array}$ \\
\hline $\begin{array}{l}\text { 3. Calderón-Ospina, C. A., } \\
\text { \& Nava-Mesa, M. O. }\end{array}$ & $\begin{array}{l}\text { Deficiência; problema de saúde; } \\
\text { Manifestações neurológicas. }\end{array}$ & $\begin{array}{l}\text { B Vitamins in the nervous system: Current } \\
\text { knowledge of the biochemical modes of action and } \\
\text { synergies of thiamine, pyridoxine, and cobalamin, } \\
2020 \text {. }\end{array}$ \\
\hline $\begin{array}{l}\text { 4. de Sousa, D. J. M., de } \\
\text { Araújo, D. S. C., de Sousa, } \\
\text { L. L. C., Aires, I. O., } \\
\text { Oliveira, I. K. F., \& } \\
\text { Alencar, M. D. S. S. }\end{array}$ & $\begin{array}{l}\text { Idade de risco; faixa etária vulnerável; } \\
\text { manifestações mais severas; déficits } \\
\text { cognitivos. }\end{array}$ & $\begin{array}{l}\text { Influência da vitamina B12 e do ácido fólico sobre } \\
\text { distúrbios cognitivos em idosos, } 2020 \text {. }\end{array}$ \\
\hline $\begin{array}{l}\text { 5. Hannibal, L., Lysne, V., } \\
\text { Bjørke-Monsen, A. L., } \\
\text { Behringer, S., Grünert, S. } \\
\text { C., Spiekerkoetter, U., ... } \\
\text { \& Blom, H. J. }\end{array}$ & $\begin{array}{l}\text { Vitamina B12, molécula precursoras de } \\
\text { serotonina, noradrenalina e dopamina; } \\
\text { homocisteína, ácido metilmalônico e } \\
\text { alterações neurológicas. }\end{array}$ & $\begin{array}{l}\text { Biomarkers and algorithms for the diagnosis of } \\
\text { vitamin B12 deficiency, } 2016 \text {. }\end{array}$ \\
\hline 6. Johnson, L. E. & $\begin{array}{l}\text { Doenças que diminuem o potencial de } \\
\text { absorção da vitamina B12. }\end{array}$ & Deficiência de vitamina B12, 2020. \\
\hline $\begin{array}{l}\text { 7. Langan, R. C., \& } \\
\text { Goodbred, A. J. }\end{array}$ & $\begin{array}{l}\text { Condições prevalentes que reduzem a } \\
\text { capacidade de biossíntese da vitamina B12. }\end{array}$ & $\begin{array}{l}\text { Vitamin B12 deficiency: recognition and } \\
\text { management,2017. }\end{array}$ \\
\hline $\begin{array}{l}\text { 8. Maia, Y. L. M., Silva, } \\
\text { M. G. D., \& Passos, X. S. }\end{array}$ & $\begin{array}{lcc}\text { Bactérias intestinais, síntese } & \mathrm{e} \\
\text { armazenamento de vitamina B12. } & \end{array}$ & $\begin{array}{l}\text { Vitamina b12 (cobalamina): aspectos clínicos de sua } \\
\text { deficiência, } 2019 .\end{array}$ \\
\hline $\begin{array}{l}\text { 9. Roda, M., di Geronimo, } \\
\text { N., Pellegrini, M., \& } \\
\text { Schiavi, C. }\end{array}$ & $\begin{array}{l}\text { Doença neurológica, degenerativa, sistema } \\
\text { nervoso. }\end{array}$ & $\begin{array}{l}\text { Nutritional optic neuropathies: state of the art and } \\
\text { emerging evidences, } 2020 \text {. }\end{array}$ \\
\hline $\begin{array}{l}\text { 10. Wolffenbuttel, B. H., } \\
\text { Wouters, H. J., Heiner- } \\
\text { Fokkema, M. R., \& van } \\
\text { der Klauw, M. M. }\end{array}$ & $\begin{array}{l}\text { Manifestações neurológicas; deficiência } \\
\text { nutricional, população de risco. }\end{array}$ & $\begin{array}{l}\text { The many faces of cobalamin (vitamin B12) } \\
\text { deficiency, } 2019 .\end{array}$ \\
\hline
\end{tabular}

Fonte: Elaborado pelas autoras.

\section{Resultados e Discussão}

\subsection{Mecanismo de absorção da vitamina B12}

Para que haja a absorção da cobalamina no sistema digestivo, é essencial que o trato gastrointestinal esteja em prefeitas condições, sendo que esse micronutriente pode ser encontrado em dietas a base de proteínas. No estômago ela é liberada por meio da ação do ácido gástrico e da pepsina e une-se a uma proteína transportadora à haptocorrina secretada pelas glândulas salivares e mucosa gástrica, assim, ela é conduzida para o duodeno, onde a haptocorrina é digerida pelas proteases pancreáticas, liberando a cobalamina, assim ela se liga ao fator intrínseco formando um complexo (Filipović, 2007). O fígado é o principal reservatório dessa vitamina no organismo, com o poder de armazenamento de 2 a $5 \mathrm{mg}$ de vitamina B12.

A absorção bioquímica da vitamina B12 em mamíferos é bastante complexa e altamente eficiente, o mecanismo envolve três proteínas de transporte distintas: haptocorrina (também conhecida como transcobalamina I), fator intrínseco gástrico e transcobalamina II, que suportam o transporte da vitamina B12 da boca para as células. A B12, inicialmente ligada às proteínas dietéticas (P), é liberada pela digestão péptica no ambiente ácido do estômago e primeiro se liga à haptocorrina (HC). HC é uma glicoproteína secretada pelas células parietais gástricas (mucosa gástrica), células do fígado e glândulas exócrinas e está presente em uma variedade de secreções, como saliva, plasma e bile. Devido à sua alta afinidade para a B12 em condições ácidas (pH <3), o HC evita que a B12, sensível ao ácido, sofra hidrólise à medida que se move através do estômago. (Pettenuzzo et al.,2016). Segundo Alpers et al. (2012) o fator intrínseco (FI) é uma glicoproteína secretada, produzida pelas células parietais da mucosa gástrica humana, sendo sua função promover a absorção da vitamina essencial cobalamina (Cbl) no íleo. 


\subsubsection{Absorção prejudicada}

A vitamina B12 é absorvida pelos seres humanos no íleo, que é responsável pelo convertimento dos substratos ácido metilmalônico e homocisteína nos referentes produtos succinil-coenzima A e metionina, portanto, a ausência desta vitamina, acarretaria o aumento dos substratos e a deficiência dos produtos formados. A má absorção da cobalamina proveniente de alimentos é a principal causa de deficiência dessa vitamina em adultos (Filipović, 2007). Apesar de ocorrer síntese dessa vitamina pelas bactérias intestinais, presentes no organismo humano, não é o suficiente, pois ocorre distante dos sítios de absorção da mesma, o que faz com que seja praticamente extinta em sua totalidade pelas fezes (Souza et al. 2013).

Estudos apontam que distúrbios do intestino delgado (ex: doença inflamatória intestinal, doença celíaca, câncer, distúrbios pancreáticos ou biliares) também diminuem o potencial de absorção da vitamina B12. Parasitas como infestação de vermes de peixes ou síndrome da alça cega onde a parte superior do intestino delgado, perde os movimentos peristálticos, estase do conteúdo intestinal causando crescimento excessivo de bactérias, podendo ser também apontado como causador da má absorção (Johnson, 2019). Outra causa que pode interferir na absorção é a presença de atrofia da mucosa gástrica e células autoimunes para os fatores intrínsecos que são indispensáveis para absorver a vitamina B12, a presença da bactéria $H$. pylori, é uma das hipóteses de causar a deficiência de vitamina B12 nos idosos, pois tais eventos têm em comum a má absorção para esta vitamina (Barnabé et al., 2015).

São vários os fatores que podem interferir na absorção da vitamina B12, como uma dieta insuficiente ou uma síndrome de má absorção pode levar ao déficit dessa vitamina. Além disso, determinadas medicações podem intervir na absorção, metabolismo e disponibilidade da vitamina B12, alguns exemplos são: trimetoprim, metotrexato, fenitoína, fenobarbital e sulfazalazinas (Brito et al., 2012). Segundo Souza et al. (2013) o medicamento mais utilizado para tratamento de doença do refluxo gastroesofágico, esofagite erosiva associada com doença do refluxo gastroesofágico, condições hipersecretórias (Síndrome de Zollinger-Elison, hipergastrinemia, mastocitose sistêmico e adenoma endócrino múltiplo), úlceras pépticas e terapia da erradicação de Helicobacter pylori, são fármacos inibidores de bomba de prótons, são medicamentos autorizados pela ANVISA, mas a venda seria sob prescrição médica, dentro da Relação Nacional de Medicamentos Essenciais (RENAME) do Brasil (Pimenta et al., 2016). Um dos efeitos desses medicamentos é a diminuição da acidez estomacal, motivos pela qual há a má absorção de nutrientes que o corpo retira da dieta, como a vitamina B12 (Lima \& Filho, 2014).

\subsection{Deficiência da vitamina $\mathrm{B} 12$}

Devido a este micronutriente ser produzido no intestino dos animais e pelo fato das plantas não necessitarem dele, a melhor maneira de adquirir a vitamina B12 é pelo consumo de alimentos de origem animal (carnes, ovos e leites). Além disso, após a ingestão, essa vitamina precisa ser combinada com uma proteína produzida pelo estômago para ser devidamente absorvida, caso contrário, a vitamina B12 permanece no intestino e posteriormente é liberada pelo corpo humano junto às fezes (Johnson, 2020). Sendo assim, a deficiência da vitamina B12 pode ocorrer quando não há a ingestão em quantidade suficiente ou não há a absorção de forma adequada pelo organismo, pois quando há consumo de quantidades suficientes de vitamina B12 e, ainda assim, há a confirmação clínica de deficiência de B12, então a má absorção pode ser a possível causa para esse diagnóstico (Stabler et al., 2013).

Neurotransmissores como a serotonina, noradrenalina e dopamina dependem de moléculas precursoras, tais como a vitamina B12 e o ácido fólico, onde dessa forma, a deficiência desse micronutriente está relacionada a alterações de humor. Depressão e comprometimento cognitivo também estão associados ao tema, onde a vitamina B12 é utilizada como coenzima para a metionina sintase citosólica (MS) e a metilmalonil-CoA mutase mitocondrial (MCM) e quando há a deficiência dessa vitamina, ocorre o aumento na concentração de homocisteína e ácido metilmalônico ocasionando as alterações neurológicas. 
Sendo assim, torna-se benéfico o monitoramento dos níveis de cobalamina, com o objetivo de prevenção de possíveis agravos (De Sousa et al., 2020; Hannibal et al.,2016). Wolffenbuttel et al. (2019) relataram que por muitas vezes, inicialmente, a deficiência da vitamina B12 era relacionada exclusivamente à anemia, porém, com o passar do tempo, pode-se observar também anormalidades neurológicas, como a degeneração da medula espinhal, que é considerada como uma das manifestações mais temidas devido a possibilidade de se tornar permanente.

Serin e Arslan (2019) em seu estudo citam que hipotonia (tônus muscular, que provoca a incapacidade de engatinhar, levantar ou mesmo sentar) e atraso do neurodesenvolvimento são casos frequentemente encontrados em bebês com deficiência da vitamina B12, onde, após realizarem a suplementação, puderam observar uma melhora clínica dos pacientes. Além disso, obtiveram sucesso ao tratar espasmos infantil com este micronutriente, partindo do pressuposto que vários estudos correlacionaram epilepsia com a deficiência de vitamina B12. Gatica-Domínguez et al. (2018) demonstram, através de seu trabalho, que a ingestão de vitamina B9 e vitamina B12 na primeira infância pode ajudar a saúde mental e o desenvolvimento das crianças, visto que a vitamina B12 exerce função importante na conversão de fosfatidiletanolamina para fosfatidilcolina, conrrespondendo a 14 e $11 \%$ da mielina do sistema neural central, respectivamente, e portanto, facilitando a rápida comunicação entre os neurônios.

\subsection{População com pré-disposição à falta de vitamina B12}

Segundo Wolffenbuttel et al. (2019) a má absorção de vitamina B12 pode ser mais proeminente em indivíduos mais velhos, tornando essas pessoas um grupo de maior risco de deficiência sintomática de vitamina B12. Com a senescência, as células epiteliais do estômago reduzem sua capacidade de biossintetizar as proteínas transportadoras de cobalamina e a capacidade de secreção gástrica é necessária tanto para a dissociação da vitamina B12 dos alimentos, quanto para a ligação aos portadores (Rizzo et al., 2016). Pacientes com mais de 50 anos podem não ser capazes de absorver a vitamina B12 adequadamente, e para prevenção, devem consumir alimentos enriquecidos (Langan et al., 2017).

Um novo grupo de indivíduos com deficiência de vitamina B12 está se desenvolvendo rapidamente à medida que o número de pessoas submetidas à cirurgia bariátrica em todo o mundo está aumentando (Wolffenbuttel et al., 2019). O reconhecimento clínico dessas deficiências nutricionais é fundamental, pois são passíveis de correção e, se não forem corrigidas, déficits neurológicos permanentes podem ocorrer (Goodman, 2015).

Como a vitamina B12 está presente principalmente em produtos alimentícios de origem animal, os vegetarianos e veganos correm um risco especialmente alto de desenvolver deficiência de vitamina. Se o consumo de alimentos de origem animal é muito baixo ou ausente, a escassa presença de cobalamina na dieta torna imprescindível sua introdução, seja por meio de suplementos ou alimentos fortificados (Rizzo et al., 2016).

\subsection{Relação entre ácido fólico e a falta de vitamina B12}

A vitamina B12 e o ácido fólico têm um papel crucial em diversas reações bioquímicas, sendo essencial para o funcionamento do organismo e necessário para a síntese de neurotransmissores e para a redução dos níveis de homocisteína a nível cerebral. Uma escassez desses micronutrientes podem causar danos neurológicos, cardiovasculares, hematológicos e ósseos, estando diretamente relacionadas com o metabolismo da homocisteína (Paniz et al., 2005).

O ácido fólico está presente em diversas frutas e em vegetais, e pode ser encontrado em maiores quantidades no feijão, a sua deficiência ocorre pela ingestão inadequada ou pela má absorção dos folatos presentes nos alimentos (Santana, 2016). De acordo com Brigitta (2012), a vitamina B12 e o ácido fólico são essenciais para o funcionamento adequado do cérebro e comete de forma positiva no desempenho cognitivo e no humor dos indivíduos, pois participam ativamente no catabolismo da homocisteína ao realizar a sua metilação. A deficiência destes nutrientes dificulta a execução de diversas reações enzimáticas, 
aumentando as concentrações de homocisteína, o que pode desencadear um quadro depressivo e comprometimento cognitivo (Sousa; 2022).

O ácido fólico também exerce como transportador de carbono para a formação de ferro heme, desta forma, uma diminuição desse nutriente provocaria o surgimento de anemia, pois não se conseguiria produzir e manter novas células sanguíneas (Coussirat, 2010). Dentre o conjunto formado pelas anemias, uma das mais intrigantes é a anemia megaloblástica, que sua causa pode ser de diferentes fatores, dentre eles destacam-se a deficiência de vitamina B12 e de folatos (Paniz, 2015). A anemia megaloblástica, resultantes da deficiência de ácido fólico e/ou vitamina B12, retrata-se pela presença de eritoblastos com núcleo aumentado e uma cromatina imatura, finamente pontilhado, enquanto o RNA continua a produzir proteínas citoplasmáticas, gerando células grandes com citoplasma maduro e de grande volume. Esses eritoblastos mais volumosos são chamados de megaloblastos e, por esse motivo, as anemias por deficiência de ácido fólico ou vitamina B12 são denominadas anemias megaloblásticas (COUSSIRAT, 2010).

\subsection{Principais doenças neurológicas}

Como a vitamina B12 está envolvida em tantas vias essenciais, sua deficiência é um tremendo problema de saúde. No entanto, os sintomas diferem fortemente em gravidade e podem se manifestar como condições leves ou distúrbios com risco de morte (Calderón-Ospina et al.,2019). A apresentação clínica da deficiência de B12 é insidiosa e inclui manifestações hematológicas (como por exemplo: palidez, tontura, taquicardia e falta de ar), manifestações gastrointestinais (perda de peso e diarreia) e manifestações neurológicas. Os distúrbios de deficiência neurológica incluem, mas não sendo limitados, a esclerose combinada subaguda (SCD) da medula espinhal, polineurite, neuropatia, mielopatia, atrofia do nervo óptico e função cognitiva prejudicada. Em particular, como coenzima na reação da metil malonil-CoA mutase, a vitamina B12 é crucial na síntese de mielina e sua deficiência leva a uma incorporação de ácidos graxos anormais em lipídios neuronais, alterando a transmissão nervosa correta (Roda et al., 2020). Segundo Sun et al. (2019) a SCD da medula espinhal é uma doença neurodegenerativa das colunas dorsal e lateral e nervos periféricos, sendo a doença neurológica mais comum causada por deficiência de vitamina B12, visto que a cobalamina é necessária para o desenvolvimento e mielinização inicial do sistema nervoso central e para a manutenção de sua função normal.

Como neuropatias e função cognitiva prejudicada, entende-se, de acordo com Madureira et al. (2018) que dos vários tipos de demência apresentados pela população idosa, a Doença de Alzheimer (DA) é a principal deles. A DA é caracterizada por perda das funções cognitivas de forma progressiva, como falhas na memória, aprendizagem e linguagem, que tendem a se agravar com o avanço da doença. A DA é um distúrbio neurodegenerativo grave do cérebro, caracterizado por placas betaamilóides extracelulares, emaranhados fibrilares de tau intraneuronais, morte celular de neurônios colinérgicos, patologia vascular e inflamação. Baixos níveis de vitamina B12 e folato foram relatados como afetando funções cognitivas, como memória no envelhecimento saudável e demência. Ambos são usados na avaliação clínica padrão da deterioração cognitiva na velhice. A vitamina B12 e o folato são determinantes dependentes de nutrientes da homocisteína e representam fatores de risco de conversão para demência (Blasko et al.,2021).

Ainda para McCarter et al. (2019) há evidências de disfunção colinérgica importante no início do curso da doença de Parkinson (DP). A acetilcolina é um neurotransmissor primário em muitos grupos neuronais no sistema nervoso central (SNC). A enzima responsável pela síntese de acetilcolina é a colina aciltransferase (ChAT), que produz acetilcolina através da transferência de um grupo acetil para colina. A síntese de acetilcolina é regulada principalmente pela quantidade de colina livre e sua captação pré-sináptica por meio de um transportador de colina de alta afinidade. A relação entre o metabolismo da vitamina B12 e da acetilcolina é complexa. Essa interação decorre do ciclo de transmetilação, que depende da vitamina B12 e regula indiretamente a disponibilidade de colina. Os níveis de vitamina B12 em pacientes com DP demonstraram ser mais baixos do 
que os controles. Níveis mais baixos de vitamina B12 também estão associados a maior estágio de Hoehn-Yahr (classificação usada para determinar o estágio da Doença de Parkinson.), comprometimento cognitivo e neuropatia em pacientes com DP. Além disso, poucas quantidades de vitamina B12 também se correlacionam com piora mais rápida da capacidade ambulatorial em pacientes com DP.

\subsection{Política pública para prevenção e combate à falta de nutrientes}

A Política Nacional de Promoção da Saúde inclui como um de seus assuntos prioritários a elevação de ações relativas à alimentação apropriada e saudável (Brasil, 2014). As diretrizes de promoção da nutrição saudável e prevenção de deficiências nutricionais estão também demonstradas no PLANSAN (Plano Nacional de Segurança Alimentar e Nutricional 2016/2019) obra da articulação de 15 ministérios e organizado pela Câmara Interministerial de Segurança Alimentar e Nutricional unida com o Conselho Nacional de Segurança Alimentar e Nutricional (Brasil, 2018), que distingue, entre seus desafios, o controle e a prevenção das consequências decorrentes da má alimentação, onde são incluídas as deficiências de micronutrientes.

Em 2019 foi feito um estudo onde foram coletados dados de crianças até 5 anos, para verificar a falta de macro e micronutrientes nesses indivíduos. Os dados foram coletados em todo território nacional. A pesquisa conseguiu obter amostras de sangue de $70 \%$ das crianças elegíveis de 6 a 59 meses e teve uma logística complexa de coleta, transporte e análise padronizada dos exames laboratoriais. A alimentação foi investigada por meio de questionário e recordatório alimentar de 24 horas em quase todas as crianças da amostra. As informações foram efetivas para auxiliar a reorganizar as políticas públicas de alimentação e nutrição infantil nos anos que virão. Nessa pesquisa, dados inéditos apontaram que 14,2\% das crianças brasileiras de até 5 anos de idade apresentam carência da vitamina B12, que ajuda no funcionamento do metabolismo. A diferença entre as regiões do país é grande, com maior ausência no Norte (28,5\%), após o Sudeste (14\%), no Centro-Oeste (12\%), no Nordeste (11,7\%) e no Sul (9,6\%) (SILVA, 2021). Com esse estudo fica claro que precisamos de um olhar mais atento sobre as necessidades de ter nas farmácias públicas, suplementos de vitaminas como a B12 e o fornecimento de alimentação apropriada para as populações mais carentes, visto que quando precisam, na maioria das vezes, a população não encontra suas necessidades atendidas.

\section{Considerações Finais}

A vitamina B12 é responsável por importantes funções metabólicas e neurotróficas no organismo humano, onde pacientes que apresentam deficiência desse micronutriente possuem vários sintomas, como anemia megaloblástica, neuropatia periférica e sintomas psiquiátricos, entre eles transtornos depressivos e cognitivos. Portanto, esse tema de ampla discussão - a deficiência de vitamina B12 - é uma epidemia invisível, que não causa somente anemia perniciosa, mas compromete inúmeras partes do corpo e colabora para a fisiopatologia de muitas enfermidades. Por ser de simples diagnóstico e tratamento, realizá-los de forma precoce gera resultados excelentes. A sugestão é que os pacientes que apresentarem quaisquer sinais ou sintomas relacionados, possivelmente, com a deficiência da vitamina B12, busquem a confirmação clínica e realize os devidos procedimentos para que consigam os níveis desejáveis e importantes da mesma. Sendo assim, torna-se necessário esclarecer a seriedade da cobalamina para o desenvolvimento e funcionamento correto do organismo, visando futuramente não se tornar um grave problema de saúde pública. Além disso, apesar dos grandes avanços nos últimos anos, muito está ainda por descobrir e para futuros trabalhos sugere-se mais investigações que tragam novos tratamentos e formas de prevenção, resultando numa melhoria da qualidade vida do ser humano.

\section{Agradecimentos}

As autoras desejam agradecer ao Instituto Federal Goiano - Campus Rio Verde por todo o apoio oferecido durante a 
execução do trabalho apresentado.

\section{Referências}

Abrantes, V. R. S., \& Tabai, K. C. (2013). Alimentos fortificados: análise das declarações em rótulos de leites em pó e alimentos em pó à base de soja fortificados com vitaminas e minerais. Oikos: Revista Brasileira de Economia Doméstica, 24(1), p. 053-072

Alpers, D. H., \& Russell-Jones, G. (2013). Gastric intrinsic factor: The gastric and small intestinal stages of cobalamin absorption. A personal journey. Biochimie, 95(5), 989-994.

Blasko, I., Defrancesco, M., Oberacher, H., Loacker, L., Kemmler, G., Marksteiner, J., \& Humpel, C. (2021). Plasma phosphatidylcholines and vitamin B12/folate levels are possible prognostic biomarkers for progression of Alzheimer's disease. Experimental Gerontology, $147,111264$.

Brasil. (1998). Portaria no 31, de 13 de janeiro de 1998. Regulamento Técnico referente a Alimentos Adicionados de Nutrientes Essenciais. Secretaria de Vigilância Sanitária, Ministério da Saúde.

Brasil. (2014). Política Nacional de Promoção da Saúde: PNaPS: revisão da Portaria MS/GM no 687, de 30 de março de 2006 / Ministério da Saúde, Secretaria de Vigilância à Saúde, Secretaria de Atenção à Saúde. Brasília: Ministério da Saúde.

Brasil. (2018). Secretaria de Atenção à Saúde. Departamento de Atenção Básica Coordenação-Geral de Alimentação e Nutrição. Balanço de gestão 2015 - 2018. Brasília: Ministério da Saúde.

Bravo, P., \& Ibarra, J. (2014). Compromiso neurológico y hematológico por déficit de vitamina B12 en lactante hijo de madre vegetariana: Caso Clínico. Revista chilena de pediatría, 85(3), 337-343.

Brito, A., Hertrampf, E., Olivares, M., Gaitán, D., Sánchez, H., Allen, L. H., \& Uauy, R. (2012). Folatos y vitamina B12 en la salud humana. Revista médica de Chile, 140(11), 1464-1475.

Calderón-Ospina, C. A., \& Nava-Mesa, M. O. (2020). B Vitamins in the nervous system: Current knowledge of the biochemical modes of action and synergies of thiamine, pyridoxine, and cobalamin. CNS neuroscience \& therapeutics, 26(1), 5-13.

Combs Jr, G. F., \& McClung, J. P. (2016). The vitamins: fundamental aspects in nutrition and health. Academic press.

Costa, T., \& Santos, V. F. N. (2018). Aceitabilidade de barra de cereal fonte de proteína e vitamina b12 por ovo-lacto-vegetarianos. Demetra.

Coussirat, C. (2010). Prevalência de deficiência de vitamina B12 e ácido fólico e sua associação com anemia em idosos atendidos em um Hospital Universitário (Master's thesis, Pontifícia Universidade Católica Do Rio Grande Do Sul).

de Sousa, D. J. M., de Araújo, D. S. C., de Sousa, L. L. C., Aires, I. O., Oliveira, I. K. F., \& Alencar, M. D. S. S. (2020). Influência da vitamina B12 e do ácido fólico sobre distúrbios cognitivos em idosos. Research, Society and Development, 9(1), e38911553-e38911553.

Duplessis, M., Pellerin, D., Cue, R. I., \& Girard, C. L. (2016). Factors affecting vitamin B12 concentration in milk of commercial dairy herds: An exploratory study. Journal of dairy science, $99(6), 4886-4892$.

Filipović, A. (2007). The importance of holotranscobalamin measurement. Journal of Medical Biochemistry, 26(3), 227-230.

Gatica-Domínguez, G., Rothenberg, S. J., Torres-Sánchez, L., de Lourdes Schnaas, M., Schmidt, R. J., \& López-Carrillo, L. (2018). Ingesta de folato y vitamina B12 en la dieta del niño y su neurodesarrollo a los 24 y 30 meses de edad. Salud Pública de México, 60(4), $388-394$.

Goodman, J. C. (2015). Neurological complications of bariatric surgery. Current neurology and neuroscience reports, 15(12), 1-7.

Hannibal, L., Lysne, V., Bjørke-Monsen, A. L., Behringer, S., Grünert, S. C., Spiekerkoetter, U., ... \& Blom, H. J. (2016). Biomarkers and algorithms for the diagnosis of vitamin B12 deficiency. Frontiers in molecular biosciences, 3, 27.

Herrmann, W., Schorr, H., Obeid, R., \& Geisel, J. (2003). Vitamin B-12 status, particularly holotranscobalamin II and methylmalonic acid concentrations, and hyperhomocysteinemia in vegetarians. The American journal of clinical nutrition, 78(1), 131-136.

Johnson, L. E. (2020). Deficiência de vitamina B12. Manual MSD: Versão Saúde para a Família. Disponível em: https://www.msdmanuals.com/ptbr/casa/dist\%C3\%BArbios-nutricionais/vitaminas/defici\%C3\%AAncia-de-vitamina-b12.

Langan, R. C., \& Goodbred, A. J. (2017). Vitamin B12 deficiency: recognition and management. American family physician, 96(6), 384-389.

Liberati, A., Altman, D. G., Tetzlaff, J., Mulrow, C., Gøtzsche, P. C., Ioannidis, J. P., ... \& Moher, D. (2009). The PRISMA statement for reporting systematic reviews and meta-analyses of studies that evaluate health care interventions: explanation and elaboration. Journal of clinical epidemiology, 62(10), e1-e34.

Lima, A. P. V., \& Filho Neto, M. D. A. (2013). Efeitos em longo prazo de inibidores da bomba de prótons. BJSCR.

Madureira, B. G., Pereira, M. G., Avelino, P. R., Costa, H. S., \& Menezes, K. K. P. D. (2018). Efeitos de programas de reabilitação multidisciplinar no tratamento de pacientes com doença de Alzheimer: uma revisão sistemática. Cadernos Saúde Coletiva, 26, 222-232.

López, B. C. (2019). Macarrão de quinoa e semolina fortificado com vitamina B12 (dissertação de doutorado, Universidade ISALUD).

Maia, Y. L. M., Silva, M. G. D., \& Passos, X. S. (2019). Vitamina B12 (COBALAMINA): Aspectos Clínicos de sua Deficiência. Referências em Saúde da Faculdade Estácio de Sá de Goiás-RRS-FESGO, 2(2). 
McCarter, S. J., Teigen, L. M., McCarter, A. R., Benarroch, E. E., Louis, E. K. S., \& Savica, R. (2019). Low vitamin B12 and Parkinson disease: potential link to reduced cholinergic transmission and severity of disease. In Mayo Clinic Proceedings (Vol. 94, No. 5, pp. 757-762). Elsevier.

Paniz, C. (2015). Efeitos do ácido fólico não metabolizado na metilação global do DNA, na expressão de RNAm dos genes de DHFR, MTHFR, interferon- $\hat{I}^{3}$, TNF-Ît土e interleucina-8, e na citotoxicidade das células NK (Doctoral dissertation, Universidade de São Paulo).

Paniz, C., Grotto, D., Schmitt, G. C., Valentini, J., Schott, K. L., Pomblum, V. J., \& Garcia, S. C. (2005). Fisiopatologia da deficiência de vitamina B12 e seu diagnóstico laboratorial. Jornal Brasileiro de Patologia e Medicina Laboratorial, 41(5), 323-334.

Pettenuzzo, A., Pigot, R., \& Ronconi, L. (2017). Vitamin B12-metal conjugates for targeted chemotherapy and diagnosis: Current status and future prospects. European Journal of Inorganic Chemistry, 2017(12), 1625-1638.

Pimenta, L. R. D. S., Soares, R. D. S., Castro, P. F. D. S., Freitas, J. G. A. D., \& Nielson, S. E. D. O. (2016). Uso indiscriminado de omeprazol em idosos e a importância da atenção farmacêutica. Revista de Trabalhos Acadêmicos-Universo-Goiânia.

Rémond, D. (2019). Quelle place pour les produits animaux dans l'alimentation de demain? INRA Productions Animales, 32(2), $147-157$.

Ribeiro, L. (2010). Dieta vegetariana: o que falta saber sobre o papel do selénio na proteção contra doenças. Concurso de Mérito acadêmico do Centro Vegetariano, Portugal, pg, 1-2.

Rizzo, G., Laganà, A. S., Rapisarda, A. M. C., Ferrera, L., Grazia, G. M., Buscema, M., \& Vitale, S. G. (2016). Vitamin B12 among vegetarians: status, assessment and supplementation. Nutrients, 8(12), 767.

Roda, M., di Geronimo, N., Pellegrini, M., \& Schiavi, C. (2020). Nutritional optic neuropathies: state of the art and emerging evidences. Nutrients, 12(9), 2653.

Rowley, C. A., \& Kendall, M. M. (2019). To B12 or not to B12: five questions on the role of cobalamin in host-microbial interactions. PLoS pathogens, 15(1), e1007479.

Santana, J. D., Costa, J. M. F. A., Silva, M. R. P., Santos, T. K. B., Esteves, D. C., Marson, R. F., \& Machado, A. R. D. S. R. (2016). Diagnóstico e exames laboratoriais da anemia megaloblástica e deficiência de vitamina B12 e ácido fólico. Revista Conexão Eletrônica, Mato Grosso do Sul, 13(1), 1-11.

Serin, H. M., \& Arslan, E. A. (2019). Neurološki simptomi nedostatka vitamina B12: analiza pedijatrijskih bolesnika. Acta clinica Croatica, 58(2.), 295-301.

Silva, A. A. M. D. (2021). Aspectos metodológicos do Estudo Nacional de Alimentação e Nutrição Infantil (ENANI-2019). Cadernos de Saúde Pública, 37, e00172121.

Slywitch, E. (2012). Guia alimentar de dietas vegetarianas para adultos. Sociedade Brasileira Vegetariana.

Sousa, L. J. D. R. (2022). Influência da suplementação com vitamina B12 e ácido fólico no tratamento de pacientes com antidepressivos: uma revisão de literatura.

Souza, I. K. F. D., Silva, A. L. D., Araújo, A. J. D., Santos, F. C. B., \& Mendonça, B. P. C. K. (2013). Análise qualitativa das alterações anatomopatológicas na mucosa gástrica decorrentes da terapêutica prolongada com inibidores da bomba de prótons: estudos experimentais x estudos clínicos. ABCD. Arquivos Brasileiros de Cirurgia Digestiva (São Paulo), 26(4), 328-334.

Stabler, S. P. (2013). Vitamin B12 deficiency. New England Journal of Medicine, 368(2), 149-160.

Sun, W., Li, G., Lai, Z., Lu, Z., Lin, Y., Peng, J., ... \& Hu, K. (2019). Subacute combined degeneration of the spinal cord and hydrocephalus associated with vitamin B12 deficiency. World Neurosurgery, 128, 277-283.

Surya, N., \& Patil, V. (2019). Profile of vitamin b12 deficiency in a urban neurology clinic in Mumbai, Maharashtra. Journal of the Neurological Sciences, 405, 241 .

Watanabe F, Bito T. (2018). Vitamin B12 sources and microbial interaction. Exp Biol Med (Maywood). 243(2):148-158.

Wolffenbuttel, B. H., Wouters, H. J., Heiner-Fokkema, M. R., \& van der Klauw, M. M. (2019). The many faces of cobalamin (vitamin B12) deficiency. Mayo clinic proceedings: innovations, quality \& outcomes, 3(2), 200-214. 